\title{
Identification of a Framework for Best Practices in Nutrition Education for Low-Income Audiences
}

\author{
Susan Baker, EdD ${ }^{1}$; Garry Auld, $\mathrm{PhD}^{1}$; Alice Ammerman, DrPH ${ }^{2,3}$; \\ Barbara Lohse, PhD, RD, $\mathrm{CDN}^{4}$; Elena Serrano, $\mathrm{PhD}^{5}$; Mary Kay Wardlaw, PhD ${ }^{6}$
}

\begin{abstract}
To promote effective low-income nutrition education programs, an expert panel of nutrition education and public health researchers built consensus around 28 best practices grouped into 5 domains (Program Design, Program Delivery, Educator Characteristics, Educator Training, and Evaluation) targeting direct delivery of nutrition education. These best practices can be used to assess program strengths, promote fidelity in delivery and evaluation, and design research to strengthen programs' evidence base. A survey of Supplemental Nutrition Assistance Program-Education nutrition education leaders helped identify staff development needs and interest relative to specific best practices. Best practices can be used to identify staff development needs among frontline educators, supervisors, and program leaders in Supplemental Nutrition Assistance Program-Education, Expanded Food and Nutrition Education Program, and other programs targeting low-income audiences.
\end{abstract}

Key Words: nutrition education, best practices, limited resource audiences, low-income, behavior change (J Nutr Educ Behav. 2020; 52:546-552.)

Accepted December 12, 2019. Published online January 18, 2020.

\section{INTRODUCTION}

Best practices are strategies supported by evidence that have been effective in achieving specific outcomes. ${ }^{1}$ Thus, when programs are implemented using best practices, confidence that positive outcomes will be achieved is increased. However, limited data exist that identify a comprehensive list of best practices for developing, delivering, and evaluating nutrition education interventions targeting lowincome audiences. Recent reviews elaborated on factors that are associated with more effective nutrition

Department of Food Science and Human Nutrition, Colorado State University, Fort Collins, $\mathrm{CO}$

2

${ }_{3}$ Center for Health Promotion and Disease Prevention, University of North Carolina at Chapel Hill, Chapel Hill, NC

${ }_{4}$ Department of Nutrition, Gillings School of Global Public Health and School of Medicine, University of North Carolina at Chapel Hill, Chapel Hill, NC

${ }_{5}$ Wegmans School of Health and Nutrition, NEEDs Center, Rochester Institute of Technology, University of Rochester School of Medicine, Rochester, NY

${ }_{6}$ Department of Nutrition, Foods, and Exercise, Virginia Polytechnic Institute and State University, Blacksburg, VA

University of Wyoming Extension, Laramie, WY

Conflict of Interest Disclosure: The authors have not stated any conflicts of interest.

Address for correspondence: Susan Baker, EdD, Department of Food Science and Human Nutrition, Colorado State University, 101 Gifford, Campus Box 1571, Fort Collins, CO 80523-1571; E-mail: susan.baker@colostate.edu practices, they do not convey a thorough list of best practices that encompass the process and content elements needed to develop effective, evidencebased interventions systematically.

Nutrition education programs targeting low-income audiences, such as the Supplemental Nutrition Assistance Program-Education (SNAP-Ed) and the Expanded Food and Nutrition Education Program (EFNEP), were a particular focus to promote greater consistency and efficacy in program planning, implementation, and evaluation, as well as management of these programs. The goal of this report was to develop a more comprehensive list of best practices in the context of program development, implementation, and evaluation.

To encourage the delineation of best practices, the US Department of Agriculture Food and Nutrition Service (administrators of SNAP-Ed) contracted with the National Institute of Food and Agriculture (administrators of EFNEP), who subcontracted with Colorado State University to identify best practices for nutrition education interventions targeting low-income audiences. Lead researchers assembled a 7-member expert panel, chosen based on tenure as nutrition education program leaders, university researchers, and/or their role within public 

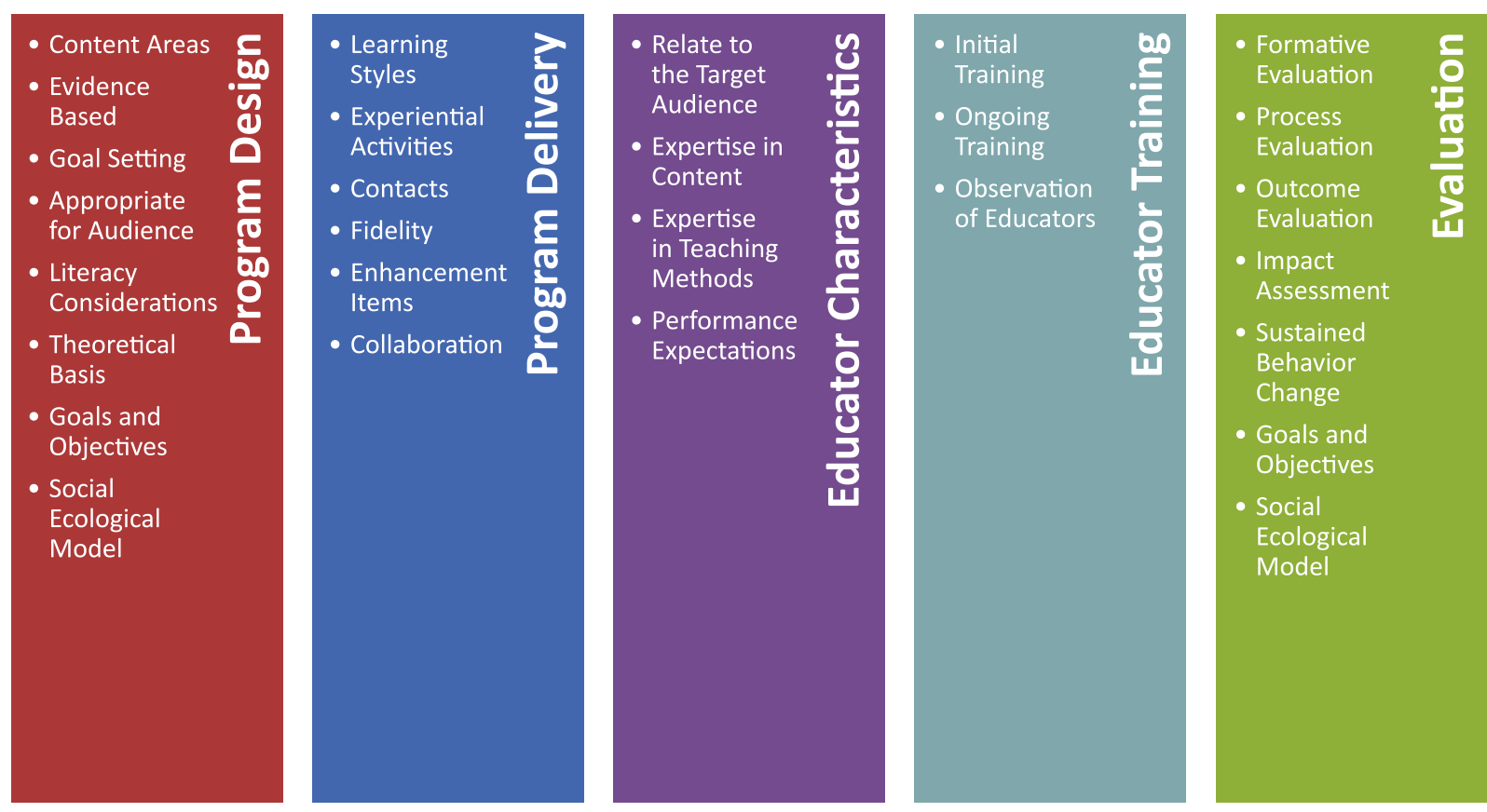

Figure 1. Best practice in nutrition education for low-income audiences: an expert panel identified 28 practices within 5 domains.

health organizations. Concurrently with panel selection, lead researchers reviewed existing literature by searching PubMed and AGRICultural OnLine Access research databases and textbooks for the key words best practice, low-income, SNAP-Ed, EFNEP, curriculum, intervention, theory, design, impact, outcomes, evaluation, and educator. Governmental literature and reports were also reviewed. The results of the literature review contributed to discussions among panel members.

In 2013, at the time of the project, investigators received fiscal year 2012 SNAP-Ed state plans and year-end reports from 50 states and 2 territories. The plans provided insights on then-current SNAP-Ed programmatic activities and provided researchers with potential case studies representing selected best practices. This analysis confirmed that direct delivery was the most prevalent nutrition education approach at the time; all SNAPEd-implementing agencies reported delivering direct education through single contacts or a series of contacts in fiscal year 2012 as required by SNAP-Ed guidance. ${ }^{9}$ In addition, EFNEP overwhelmingly delivers direct education, ${ }^{10}$ as do many other community nutrition education programs. The Healthy Hunger-Free Kids
Act of $2010^{11}$ noted that direct delivery is considered the hallmark of nutrition education and has traditionally been the most common delivery channel used in low-income nutrition education programs. Given the findings from the review of literature and 2012 SNAP-Ed state plans, the expert panel focused on identifying best practices for direct delivery of nutrition education. After this study, both SNAP-Ed and EFNEP expanded programming efforts in policy, systems, and environmental (PSE) change approaches in addition to direct education; however, this report does not address best practices in PSE. Nevertheless, the best practices included in this report could inform PSE activities.

\section{DISCUSSION}

Over a 12-month period, the panel reached consensus on 28 best practices in nutrition education for lowincome audiences; these practices were organized by panel consensus into 5 domains: Program Design, Program Delivery, Educator Characteristics, Educator Training, and Evaluation (Figure 1). ${ }^{12}$ Panel members independently developed lists of best practices, based on their own extensive experiences in nutrition education research and practice with low-income audiences, and results of the literature review. The panel then participated in multiple written exchanges and conference calls to discuss and reach consensus on the final 28 best practices. Through multiple facilitated discussions, the expert panel established face validity (the extent to which the best practices are consistently interpreted by nutrition professionals) and content validity (the extent to which the best practices represent the breath of the desired subject matter) for the best practices. ${ }^{13}$ For each best practice, the expert panel also identified several indicators that could be used by program leaders to assess how well a program met that practice. $^{12}$ Figure 2 shows examples from the Evaluation domain.

Two activities provided additional information to support the expert panel's deliberations. This included identification of potential case studies and a survey of the Association of SNAP-Ed and Nutrition Network Administrators (ASNNA) members. From the review of the 2012 SNAP-Ed state plans, case studies exemplifying best practices were identified. For the case studies, variability in delivery channel (direct, indirect, social marketing, and PSE activities), target audience (youths, adults, and older 
Indicated by:

- Expert review

- Published results of pilot studies

- Curriculum description/overview

- Published research about the development of the curriculum or intervention
To learn more:

- Contento, I.R. (2007). Nutrition education: Linking research, theory, and practice. Sudbury, MA: Jones and Bartlett Publishers. Chapter 14 Page 322

- Challenges of Conducting Effective SNAP-Ed Evaluations: A Stepby-Step Guide http://www.fns.usda.gov/sites/default/files/SNAPEDWavell Guide.pdf

- Case Study: Formative Evaluation

Process Evaluation Use of process evaluation in monitoring and decision making.

To assure intervention is implemented as designed and that intervention is continually reviewed to ensure fidelity and adapted as needed.

Indicated by:

- Program documentation

- Interviews with program developers

- Annual program reports

- Feedback from participants on usefulness and acceptability of program

- Feedback from educators on usefulness and acceptability of program

- Documented observation of educator while teaching

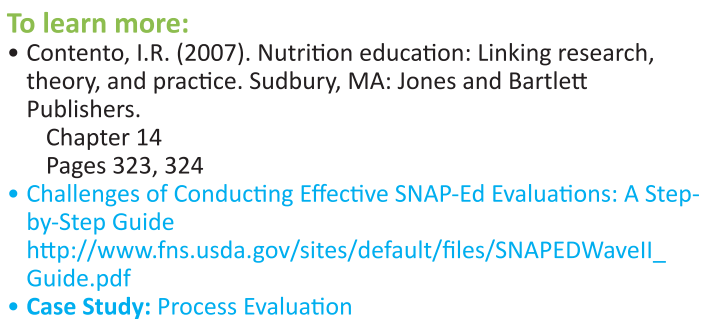

Figure 2. Selected indicators for best practices in formative and process evaluation. Other evaluation best practices are available in Baker et al. ${ }^{12}$

adults), and funding allocation (size of program) were considered. Case studies did not reflect programs that incorporated all identified best practices; rather, they demonstrated the effective use of at least 1 specific best practice. $^{12}$

Project leaders sent an e-mail survey in April, 2014 to the ASNNA listserv, which included SNAP state agency and SNAP-Ed-implementing agency representatives, to assess the confidence of the ASNNA members and SNAP-Ed stakeholders with their ability to apply each of the 28 best practices and to gauge interest in learning more about specific best practices. Respondents seemed most confident in their abilities to apply best practices related to Program Design and Delivery and less confident about those related to Evaluation (Table). For 22 best practices, $\geq$ $25 \%$ of the implementers were interested in staff development opportunities, particularly for use of the Social Ecological Model ${ }^{14}$ in Program Design and Evaluation. For 6 of 7 best practices in the Evaluation domain, $>30 \%$ of implementers were interested in participating in staff development opportunities. The most popular format for staff development options were short webinars, a series of webinars, or self-paced trainings, at $91 \%, 84 \%$, and $79 \%$, respectively. These results suggest both an interest in and need for professional development opportunities addressing best practices in nutrition education for low-income audiences.

\section{IMPLICATIONS FOR RESEARCH AND PRACTICE}

The Supplemental Nutrition Assistance Program-Education and EFNEP are US Department of Agriculture-funded nutrition education programs that target low-income audiences. These programs often use similar methods, cover similar content including the Dietary Guidelines for Americans, ${ }^{15}$ employ similar evaluation tools, and are even supervised within states by the same person (eg, in 2015, 27 state SNAP-Ed and EFNEP programs had the same coordinators ${ }^{16,17}$ ). Thus, although much of the secondary analyses was done with SNAP-Ed state plans or with the survey of
ASNNA members, the results of this study go beyond SNAP-Ed and provide valuable information for leaders of any nutrition education program.

Nutrition education programs targeting low-income audiences can benefit from incorporating specific best practices into their programs to promote greater consistency and efficacy in program planning, implementation, and evaluation. ${ }^{2,18}$ Program leaders can apply the best practices to strengthen nutrition education programming to (1) assess program strengths and shortcomings; (2) include behavior change theory and researchbased content in program design; (3) ensure evidence-based curricula, messages, and materials are appropriate for the specific target audience; (4) link evaluation to program design, program delivery, educator training, and appropriate levels of the Social Ecological Model; and (5) ensure fidelity in program delivery, educator training, data collection, and evaluation.

Self-assessment and strengthening of a program's use of best practices can lead to improved program outcomes. Indicators provided with each domain (Figure 2), although not 
Table. Supplemental Nutrition Assistance Program-Education Program Implementers' Confidence in Their Ability to Apply and Interest in Staff Development Opportunities for Best Practices $(n=60)$

\section{Best Practices, by Domain}

Program Design

Curriculum content

Research-based (based on accurate, reliable, and current research [eg, Dietary Guidelines for Americans ${ }^{15}$ ])

Goal setting (including participant behavior change goals)

Appropriate for target audience (visuals, activities, recipes, language, etc)

(Appropriate) literacy considerations

Behavior change theories

Program clearly stated goals and objectives that drive intervention and evaluation

Social Ecological Model (multiple levels)

Program Delivery

Learning styles (accommodated visual, auditory, and kinesthetic style)

Experiential activities (learner-centered methods including experiential activities with minimal lecture)

Contacts (sufficient duration and frequency to achieve learning outcomes)

Fidelity (implemented consistently and as designed)

Enhancement items (items and strategies to reinforce learning at home)

Collaboration (within and among national, state, and local health promotion initiatives)

Educator Characteristics

Relate to target audience

Expertise in content

Expertise in teaching methods

Performance expectations clearly defined and shared with educators

Educator Training

Initial training before program delivery

Ongoing training

Observations of program delivery at least annually

Evaluation

Formative evaluation

Process evaluation

Outcome evaluation

Impact assessment

Sustained behavior change

Goals and objectives measured

Social Ecological Model evaluation (each level within program design)

\section{Confidence in Ability to Interest in Staff Development Apply Best Practice ${ }^{a}$ (Mean) \\ (Yes, Definitely or Yes, Probably), \% (n)}

\begin{tabular}{|c|c|}
\hline 4.0 & $38(14)$ \\
\hline 4.2 & $43(16)$ \\
\hline 3.7 & 35 (13) \\
\hline 3.8 & $43(16)$ \\
\hline 3.7 & $43(16)$ \\
\hline 3.6 & $62(23)$ \\
\hline 4.0 & $30(11)$ \\
\hline 3.6 & $68(25)$ \\
\hline 3.6 & $58(19)$ \\
\hline 3.7 & $55(18)$ \\
\hline 3.8 & $33(11)$ \\
\hline 3.8 & 55 (18) \\
\hline 3.8 & $30(10)$ \\
\hline 3.9 & $64(21)$ \\
\hline 3.3 & 65 (17) \\
\hline 3.4 & 46 (12) \\
\hline 3.4 & $85(22)$ \\
\hline 3.6 & $73(19)$ \\
\hline 3.3 & $70(19)$ \\
\hline 3.4 & $85(23)$ \\
\hline 3.5 & $74(20)$ \\
\hline 3.4 & $63(19)$ \\
\hline 3.4 & $73(22)$ \\
\hline 3.4 & $67(20)$ \\
\hline 3.1 & $83(25)$ \\
\hline 3.0 & $80(24)$ \\
\hline 3.6 & $57(17)$ \\
\hline 3.0 & $93(28)$ \\
\hline
\end{tabular}

a Likert scale: $1=$ not comfortable with ability to apply this best practice; $2=$ understand the concept but not comfortable applying it; 3 = fairly comfortable with best practice and my ability to apply it; $4=$ confident in ability to apply the best practice; $5=$ consider myself an expert.

comprehensive, can serve as resources for program leaders when determining if and how well best practices are being implemented in their programs. In addition, the case studies from SNAP-Ed programs, provided in the report on the SNAP Web site, ${ }^{12}$ offer examples of ways to implement specific best practices. Nutrition education program leaders might also consider results from the survey of ASNNA membership described earlier
(Table) when planning professional development and performance management for themselves and other professional staff members. For example, a relatively high number of survey respondents indicated an 
interest in staff development related to several Evaluation best practices.

Ideally, behavior change theories drive the design and delivery of nutrition education, because efficacy is increased with the appropriate use of theory. ${ }^{2,19,20}$ Multiple theories have been used with low-income audiences, $^{21}$ most commonly, the Health Belief Model, Theory of Planned Behavior, Social Cognitive Theory, and Transtheoretical Model. ${ }^{21-23}$ Theory aids program planners (SNAP-Ed implementers) in defining both a target audience and proven methods for producing behavior change within that audience. Some theories are more appropriate with respect to specific learning objectives and/or target audiences. $^{1,23}$ In addition to a theoretical basis, nutrition education programs are strengthened when grounded in research. An evaluation of a curriculum in a peer-reviewed journal, ${ }^{1,24}$ a list of references used in developing a curriculum, and expert panel reviews ${ }^{1,25}$ provide support for education materials and strategies being evidence-based.

When developing and delivering evidence-based curricula, messages, and materials, nutrition educators ideally consider characteristics of their target audience, including their reading level, age, and cultural background. ${ }^{1,18}$ The use of age- and literacy-appropriate visuals and activities to engage the target audience is important. ${ }^{1}$ Food preparation strategies and recipes are more effective when they support learning objectives and are appropriate for the economic status and culture of the target population.

Evaluation efforts are preferably integrated into program design, program delivery, educator training, and appropriate levels of the Social Ecological Model. When selecting evaluation measures, the purpose, duration, and intensity of an intervention are factors to consider, ${ }^{26,27}$ as well as any need to collect objective (non-selfreport) assessments. ${ }^{28}$ Tailoring evaluation tools to the delivery channels, targeted behavior changes, selected theories, dosage of intervention, and characteristics of the target audience is essential. ${ }^{27,29}$ Evaluation planning is part of initial program planning. A comprehensive evaluation plan typically involves several evaluation stages (formative, process, outcome, and impact) that occur at different times in the intervention for different purposes. $^{27,30}$ Sound evaluations determine whether participants are gaining skills from experiential learning, goal setting, and other kinesthetic learning activities. ${ }^{1}$ When programs are implemented using $\geq 1$ level of the Social Ecological Model, ${ }^{14}$ evaluation of each level is necessary to determine whether participants are gaining knowledge and/or learning skills as intended.

Effective initial or ongoing training for nutrition educators includes information relevant to evaluation purposes and protocols, identified as the area of greatest need in the survey. ${ }^{31,32}$ If educators are involved in collecting evaluation data, appropriate training will allow them to collect valid data with high fidelity that can better capture the effectiveness of the program. $^{33}$

Fidelity refers to implementation of interventions and evaluations consistently and as designed. ${ }^{34-36}$ When curricula are developed using appropriate theory and content, the likelihood that the efficacy of an intervention will be replicated in new settings is enhanced if the curricula are delivered as designed (ie, with fidelity). ${ }^{2,34-36}$ Using a curriculum in its entirety rather than piecing together multiple resources is more appropriate, because this helps to ensure fidelity to the original design, including the theoretical basis and educational content. ${ }^{1,25}$ Any adaptations to curricula must retain critical design aspects to maintain the evidence base. $^{18}$

When multiple sites and educators implement the same intervention with high fidelity, the aggregation of program outcomes becomes feasible and broadens the generalizability of results. Frontline staff must understand the importance of curriculum fidelity and know how to maintain it. This understanding arises from consistent and thorough training on the importance of delivering the curriculum as designers intended, observations of educators to monitor fidelity, and appropriate collection of evaluation data from program participants.
Although the best practices described in this project were identified with direct education in mind, most are appropriate for PSE approaches. However, further investigation of best practices for PSE strategies is warranted. ${ }^{5,37}$

The report does not serve as a systematic review of literature. Further research is warranted to build on this report to identify current critical findings of nutrition education research across these domains that could be applied to other disciplines, such as public health and dissemination and implementation science, as well as gaps in the research that could be investigated. In addition, more comprehensive assessments of staff and supervisors' professional development requirements are needed, going beyond what is described in this report.

Nutrition educators and programs serving low-income audiences face many challenges besides the serious health issues that are often highly prevalent among this population (eg, a high incidence of almost all chronic disease $^{38}$ and obesity, ${ }^{39}$ including among children). ${ }^{40}$ Yet, future federal funding for programs benefiting lowincome audiences is at risk. ${ }^{41-43}$ Nutrition education programs must use their limited resources wisely. By incorporating specific best practices, including comprehensive evaluation strategies, and establishing evidencebased outcomes, program leaders can document a positive return on investment for stakeholders and justify continued and increased funding. ${ }^{1}$

In all likelihood, no nutrition education program will exhibit all 28 best practices. Nonetheless, Best Practices in Nutrition Education for Low-Income Audiences $^{12}$ can serve as a resource to refine and/or improve current programmatic processes, including the design, delivery, and evaluation of interventions.

\section{ACKNOWLEDGMENTS}

The authors would like to acknowledge the support of the National Institute of Food and Agriculture, US Department of Agriculture, through Award 201248757-2037 and funds from the Food and Nutrition Service, US Department of Agriculture, through Interagency Agreement No. 12-IA-22-20-235. 


\section{REFERENCES}

1. Contento I. Nutrition Education: Linking Research, Theory, and Practice. 3rd ed. Burlington, MA: Jones \& Bartlett Learning; 2015.

2. Murimi MW, Kanyi M, Mupfudze T, Amin MR, Mbogori T, Aldubayan K. Factors influencing efficacy of nutrition education interventions: a systematic review. J Nutr Educ Behav. 2017;49: 142-165.

3. Hand RK, Abram JK, Brown K, Ziegler PJ, Parrott JS, Steiber AL. Development and validation of the Guide for Effective Nutrition Interventions and Education (GENIE): a tool for assessing the quality of proposed nutrition education programs. I Nutr Educ Behav. 2015;47:308-316.

4. Abram JK, Hand RK, Parrott JS, Brown K, Ziegler PJ, Steiber AL. What is your nutrition program missing? Finding answers with the Guide for Effective Nutrition Interventions and Education (GENIE). J Acad Nutr Diet. 2015;115:122-130.

5. Haynes-Maslow L, Osborne I, Jilcott Pitts SB. Best Practices and innovative solutions to overcome barriers to delivering policy, systems and environmental changes in rural communities. Nutrients. 2018;10:1012

6. Hardison-Moody A, Bowen S, Bloom JD, Sheldon M, Jones L, Leach B. Incorporating nutrition education classes into food pantry settings: lessons learned in design and implementation. J Ext. 2015;53:6FEA4 .

7. Murimi MW, Moyeda-Carabaza AF, Nguyen B, Saha S, Amin R, Njike V. Factors that contribute to effective nutrition education interventions in children: a systematic review. Nutr Rev. 2018;76:553-580.

8. Nanney MS, LaRowe TL, Davey C, Frost N, Arcan C, O'Meara J. Obesity prevention in early child care settings: a bistate (Minnesota and Wisconsin) assessment of best practices, implementation difficulty, and barriers. Health Educ Behav. 2016;44:23-31.

9. US Department of Agriculture Food and Nutrition Service. Supplemental nutrition assistance program education. FY 2019 SNAP-Ed plan guidance: March 2018. Washington, DC: US Department of Agriculture; 2018. https://snaped.fns. usda.gov/snap/Guidance/FY2019SNAPEdPlanGuidanceFULL.pdf. Accessed December 5, 2019.
10. US Department of Agriculture, National Institute of Food and Agriculture. The Expanded Food and Nutrition Education Program Policies. Washington, DC: National Institute of Food and Agriculture; 2017. https://nifa.usda.gov/sites/ default/files/program/EFNEP_PolicyDecember-2017-Update.pdf. Accessed December 5, 2019.

11. Healthy Hunger-Free Kids Act of 2010. Pub L No. 111-296, 124 Stat 3183, 42 USC $\S 1751$ (2010). https:// www.govinfo.gov/content/pkg/PLAW111 publ296/pdf/PLAW-111publ296. pdf. Accessed January 9, 2020.

12. Baker S, Auld G, MacKinnon C, et al. Best practices in nutrition for low-income audiences. Washington, DC: US Department of Agriculture; 2014. https:// snaped.fns.usda.gov/snap/CSUBestPractices.pdf. Accessed December 5, 2019.

13. Windsor RA. Evaluation of Health Promotion, Health Education and Disease Prevention. New York, NY: McGraw-Hill; 2004.

14. Centers for Disease Control and Prevention. The social-ecological model: a framework for prevention. Updated 2015. http://www.cdc.gov/violenceprevention/ overview/social-ecologicalmodel.html. Accessed December 5, 2019.

15. US Department of Health and Human Services, US Department of Agriculture. Dietary Guidelines for Americans 2015-2020. 8th ed. http://health. gov/dietaryguidelines/2015/guidelines/. Accessed December 5, 2019.

16. Tripp S, Helwig R, Simkins J. Supplemental Nutrition Assistance Program Education FY2015 through the Land-Grant University System. Columbus, $\mathrm{OH}$ : TEConomy Partners, LLC; 2016. https://community-nutrition-education.extension.org/wp-content/ uploads/2019/03/FY2015-SNAP-EdReport-Final.pdf. Accessed October 31, 2019.

17. US Department of Agriculture. Supplemental Nutrition Assistance Program Education evaluation framework and interpretive guide. 2016. https://snaped. fns.usda.gov/program-administration/ snap-ed-evaluation-framework. Accessed October 31, 2019.

18. Dollahite J, Fitch C, Carroll J. What does evidence-based mean for nutrition educators? Best practices for choosing nutrition education interventions based on the strength of the evidence. J Nutr Educ Behav. 2016;48:743-748.e1.

19. Guthrie JF, Stommes E, Voichick J. Evaluating food stamp nutrition education: issues and opportunities. J Nutr Educ Behav. 2006;38:6-11.

20. Noar SM, Zimmerman RS. Health behavior theory and cumulative knowledge regarding health behaviors: are we moving in the right direction? Health Educ Res. 2005;20:275290.

21. Achterberg C, Miller C. Is one theory better than another in nutrition education? A viewpoint: more is better. J Nutr Educ Behav. 2004;36:40-42.

22. Glanz K, Bishop DB. The role of behavioral science theory in development and implementation of public health interventions. Annu Rev Public Health. 2010;31:399-418.

23. Glanz K, Rimer BK, Viswanath K. Health Behavior: Theory, Research, and Practice. 5th ed. San Francisco, CA: John Wiley \& Sons; 2015.

24. Auld G, Baker S, Conway L, Dollahite J, Lambea MC, McGirr K. Outcome effectiveness of a widely adopted EFNEP Curriculum. J Nutr Educ Behav. 2015;47:19-27.

25. Natker E, Baker S, Auld G, McGirr K, Sutherland B, Cason K. Formative evaluation of EFNEP curriculum: ensuring the Eating Smart • Being Active curriculum is theory based. J Ext. 2015;53:1RIB1.

26. LeGros TA, Hartz VL, Jacobs LE. Reliability of a kid's activity and nutrition questionnaire for school-based SNAPEd interventions as part of a tiered development process. J Nutr Educ Behav. 2017;49:125-129

27. Windsor R, Clark N, Boyd NR, Goodman R. Evaluation of Health Promotion, Health Education, and Disease Prevention Programs. 3rd ed. New York, NY: McGraw-Hill; 2004.

28. Broekhuizen K, Kroeze W, van Poppel M NM, Oenema A, Brug J. A systematic review of randomized controlled trials on the effectiveness of computertailored physical activity and dietary behavior promotion programs: an update. Ann Behav Med. 2012;44:259286.

29. Contento IR, Randell JS, Basch CE. Review and analysis of evaluation measures used in nutrition education intervention research. $J$ Nutr Educ Behav. 2002;34:2-25.

30. Hamilton J, Feldman J. Planning a program evaluation: matching methodology to program status. In: Spector JM, Merrill MD, Elen J, Bishop MJ, eds. Handbook of Research 
on Educational Communications and Technology, New York, NY: Springer; 2014:249-256.

31. Byington C, Baker S. EFNEP and SNAP-ed initial paraprofessional training materials and methods. $J$ Ext. 2012;50:2TOT6.

32. Islam SN, Paddock JD, Dollahite JS. Navigating for success: quality staff training translates into improved program participant outcomes. J Nutr Educ Behav. 2015;47:188-189.

33. Baker SS, Pearson M, Chipman H. Development of core competencies for paraprofessional nutrition educators who deliver food stamp nutrition education. J Nutr Educ Behav. 2009;41:138143.

34. Blasé K, Fixsen D. Core Intervention Components: Identifying and Operationalizing What Makes Programs Work. Washington, DC: Assistant Secretary for Planning and Evaluation Research Brief, US Dept of Health and Human Services; 2013.

35. Durlak JA, DuPre EP. Implementation matters: a review of research on the influence of implementation on program outcomes and the factors affecting implementation. Am J Commun Psychol. 2008;41:327-350.

36. McHugh RK, Murray H, Barlow D. Balancing fidelity and adaptation in the dissemination of empirically supported treatments: the promise of trans diagnostic interventions. $J$ Behav Res Ther. 2009;47:946-953.

37. Leeman J, Aycock N, Paxton-Aiken A, et al. Policy, systems, and environmental approaches to obesity prevention: translating and disseminating evidence from practice. Public Health Rep. 2015;130:616-622.

38. Gregory C, Coleman-Jensen A. Food insecurity, chronic disease, and health among working-age adults. US Department of Agriculture, Economic Research report no. (ERR-235) 31. https://www.ers.usda.gov/publications $/$ pub-details $/$ ? pubid $=84466$. Accessed December 6, 2019.

39. Hales C, Carroll M, Fryar D, Ogden C. Prevalence of obesity among adults and youth: United States, 2015-2016. United States Department of Health and Human Services Centers for
Disease Control and Prevention. NCHS Data Brief. 2017:288. https:// www.cdc.gov/nchs/data/databriefs/ db288.pdf. Accessed December 5, 2019.

40. Ogden C, Carroll M, Fakhouri T, et al. Prevalence of Obesity Among Youths by Household Income and Education Level of Head of Household - United States 2011-2014. MMWR Morb Mortal Wkly Rep. 2018;67:186-189.

41. Bleich SN, Fleischhacker S. Hunger or deportation: implications of the Trump Administration's proposed public charge rule. J Nutr Educ Behav. 2019;51: 505-509.

42. Parrott S, Aron-Dine A, Rosenbaum D, Rice D, Floyd I, Romig K. Trump budget deeply cuts health, housing, other assistance for low- and moderateincome families. 2018. https://www. cbpp.org/research/federal-budget/ trump-budget-deeply-cuts-health-housing-other-assistance-for-low-and. Accessed December 5, 2019.

43. Schwarzenberg SJ, Fox CK. Protecting our nutrient safety net. J Pediatr. 2018; 202:9-10. 